\title{
Original
}

\section{Prenatal Growth Affects Serum Inhibin B Levels in Male Infants Until 18 Months of Postnatal Age}

\author{
Takanari FujII ${ }^{1)}$, Kazuo ITABASHI ${ }^{2)}$, Fumihiro MiUrA ${ }^{2)}$, \\ Shigetaka KITAZAwA ${ }^{1)}$ and you UMEDA ${ }^{1)}$
}

\begin{abstract}
The current study was undertaken to examine the correlation between serum levels of inhibin A or inhibin B and prenatal growth. The study population consisted of 53 infants born at 25-30 weeks gestation and weighing 400-3060 g ( 29 boys and 24 girls). Serum inhibin A and inhibin B were determined by sandwich enzyme-linked immunosorbent assay (ELISA) at 1-18 postnatal months of age. To assess the independent association of serum inhibin A and inhibin B with all other evaluated variables, we used a backward stepwise multiple regression analysis. Independent variables were postnatal age, body weight standard deviation (SD) score at blood sampling, gestational age, birth weight and its SD score for gestational age. In male infants, birth weight SD score and postnatal months of age were associated with inhibin $\mathrm{B}$ concentration after adjustment for other factors $(\beta=0.331$, $P=0.044 ; \beta=-0.513, P=0.03)$. The serum levels of inhibin $\mathrm{B}$ in female infants were negatively correlated with postnatal age $(\beta=-0.524, P<0.01)$. On the other hand, there was no relationship between inhibin $\mathrm{A}$ and any variable of prenatal growth. These results suggest that postnatal inhibin B secretion in male infants may be affected by prenatal growth.
\end{abstract}

Key words : inhibin, gonadal function, small for gestational age, intrauterine growth restriction

\section{Introduction}

Inhibins are structurally related dimeric proteins belonging to the transforming growth factor $\beta$ superfamily. Inhibin $\mathrm{A}$ and $\mathrm{B}$ are $\alpha-\beta \mathrm{A}$ and $\alpha-\beta \mathrm{B}$ dimers, respectively. They are characterized by the ability to inhibit follicle stimulating hormone (FSH) secretion from the pituitary gland.

In females, inhibin $\mathrm{A}$ is expressed in differentiated cells from antral follicles. Serum levels of inhibin A transiently increase in the newborn period to the levels observed in the luteal phase of the menstrual cycle but such levels are no longer detected after six months of age till puberty ${ }^{1)}$. Granulosa cells in developing follicles or lutein cells in the corpus luteum secrete inhibin $\mathrm{A}$ and $\mathrm{B}$ in response to gonadotropins and various other factors ${ }^{2}$.

In males, serum inhibin $\mathrm{A}$ is undetectable in any stage of life. Inhibin $\mathrm{B}$ is mainly

\footnotetext{
1) Children's Medical Center, Showa University Northern Yokohama Hospital, 35-1 Chigasakichuo, Tuzuki-ku, Yokohama 224-8503, Japan.

2) Department of Pediatrics, Showa University School of Medicine.
} 
secreted by Sertoli cells ${ }^{1,3)}$. It is well established that serum levels of inhibin B are transiently increased in the postnatal period and re-increased at the onset of puberty ${ }^{1)}$. It is also suggested that activation of the reproductive axis is important for Sertoli cell proliferation $^{4,5}$. However, little is known about the role of inhibin $\mathrm{A}$ and $\mathrm{B}$ in the regulation of the hypothalamic-pituitary-gonadal hormonal axis in girls during childhood and puberty.

Male infants born small for their gestational age (SGA) may have abnormal pituitarygonadal axis function and have a tendency towards hypogonadism ${ }^{6)}$. Fetal adaptation to an adverse intrauterine environment may lead to a permanent alteration of some metabolic and endocrine set points, as suggested by the fetal programming hypothesis ${ }^{7)}$.

In order to clarify the role of inhibin $\mathrm{A}$ and inhibin $\mathrm{B}$ in the regulation of the hypothalamic-pituitary-gonadal axis by prenatal growth conditions, we examined the correlation between the serum levels of these proteins and various parameters of prenatal growth.

\section{Subjects and Methods}

Data were collected between June 2004 and January 2005. A cohort of infants delivered at 25-40 weeks gestation and weighing 400-3060 g in level III neonatal intensive care units (Showa University Hospital and Showa University Northern Yokohama Hospital) was studied. The subjects were all followed up in outpatient departments of the same hospitals. The study population consisted of 29 boys and 24 girls up to 18 months of age, in good general condition. Exclusion criteria from the study were major congenital abnormality and endocrine disease. The study was approved by the Showa University Ethics Committee; written informed consent was obtained in all cases.

Venous blood samples were taken from the patients between 2:00 PM and 4:00 PM at the outpatient department. After clotting, serum was separated by centrifugation and stored at $-20^{\circ} \mathrm{C}$ until analysis. Serum inhibin A and inhibin B were measured by sandwich enzyme-linked immunosorbent assay (ELISA), (ACTIVE Inhibin A ELISA, ACTIVE Inhibin B ELISA, Diagnostic Systems Laboratories). The lower detection limits of inhibin A and inhibin B are $1 \mathrm{pg} / \mathrm{dL}$ and $7 \mathrm{pg} / \mathrm{dL}$, respectively.

Age and body weight at the time of sampling blood were recorded and the body weight standard deviation (SD) score was calculated by the standard body weight and standard deviation of Japanese infants. Gestational age, birth weight and its birth weight SD score for gestational age were evaluated from medical reports.

Results are expressed as mean \pm SD. For statistical analysis, Student's t-test and Wilcoxon rank sum test were used to assess differences among genders and serum inhibin levels in each gender. Correlation coefficients between serum inhibin levels and age were investigated by Pearson's correlation coefficient. To assess the independent association of serum inhibin A and inhibin B with all the other evaluated variables, a backward stepwise multiple regression analysis was used. Independent variables were as follows: postnatal months of age, body weight at the time of sampling blood, body weight SD score for postnatal month, gestational age, birth weight, and birth weight SD score for gestational age. Computations were performed using the Statistical Package for Social Science (SPSS Inc, Chicago, Illinois, USA). $P<0.05$ was considered significant.

\section{Results}

Clinical characteristics of the infants are shown in Table 1 . No differences were found 
Table 1. Basic clinical data on the study patients

\begin{tabular}{lccc}
\hline \multicolumn{1}{c}{ Variable } & Male $(\mathrm{n}=29)$ & Female $(\mathrm{n}=24)$ & P value \\
\hline Gestational age (weeks) & $32.8 \pm 4.4[25.1-40.1]$ & $32.3 \pm 4.2[24.1-37.9]$ & 0.68 \\
Birth weight $(\mathrm{g})$ & $1616 \pm 701[518-3060]$ & $1396 \pm 572[400-2316]$ & 0.22 \\
Birth weight SD score & $-1.4 \pm 1.4[-4.1-0.7]$ & $-1.9 \pm[-4.8--0.1]$ & 0.21 \\
Age (months) & $9.0 \pm 4.1[2.0-17.9]$ & $9.3 \pm 3.9[3.2-16.9]$ & 0.83 \\
$\begin{array}{l}\text { Body weight SD score at } \\
\text { the time of blood sampling }\end{array}$ & $-09 \pm 1.7[-3.3-3.2]$ & $-1.7 \pm 1.9[-6.3-4.2]$ & 0.12 \\
\hline
\end{tabular}

Gastational age, birth weight and age: data expressed as means $\pm \mathrm{SD}$ [max-min]. No differences were found in postnatal months of age, body weight at the time of sampling blood, body weight SD score for postnatal month, gestational age, birth weight, and birth weight SD score for gestational age

between genders in postnatal months of age, body weight at the time of sampling blood, body weight SD score for postnatal month, gestational age, birth weight and birth weight SD score for gestational age.

The individual serum levels of inhibin $A$ and inhibin $B$ in relation to age are plotted in Fig. 1. The serum levels of inhibin A were significantly lower than those of inhibin B (male : $P<0.01$, female : $P<0.01$ ). In both genders, the serum concentrations of inhibin $\mathrm{B}$ were negatively correlated with postnatal months of age in simple regression analyses (male: $\mathrm{r}=0.500, P=0.006$, female $: \mathrm{r}=0.52, P=0.009)$. Serum inhibin A was undetectable in 19 of 29 boys and in 6 of 24 girls and no significant correlations were found between serum inhibin A level and postnatal age in both genders.

In females, stepwise multiple regression analysis revealed that the inhibin B concentration was negatively correlated only with postnatal age $(P<0.01)$ and there was no relationship between inhibin $\mathrm{B}$ levels and gestational age, birth weight, birth weight SD score, body weight or body weight SD score at the time of blood sampling (Table 2). In male infants, inhibin B concentration was positively correlated with birth weight SD score $(P=0.044)$ and negatively correlated with postnatal age $(P=0.003)$ after adjustment for other factors. In both genders, serum inhibin A levels had no correlation with any clinical variables.

\section{Discussion}

Previous reports have shown that inhibin A secretion is very low compared with inhibin $\mathrm{B}$ during the neonatal period ${ }^{1,8)}$. In both genders, at less than 6 months of age, serum inhibin B levels [in healthy children born at full-term gestatin] are as high as those at puberty and then progressively fall to reach their lowest concentrations at age 4-6 years of age $^{1,9,10)}$. [That same pattern in girls is observed early, after the first month of life ${ }^{1.10)}$ ] During puberty, serum inhibin B levels increase again in both genders ${ }^{1)}$. Our subjects showed a pattern of events similar to those previously reported in infants until 18 months of postnatal age.

It is well known that the inhibin $\mathrm{B}$ level is a useful marker of spermatogenesis ${ }^{11)}$. In boys before puberty, as well as in adult men, the source of circulating inhibin $B$ is the testes. Low inhibin B levels have been observed in infants with hypogonadism ${ }^{12}$. Previous 
a) Inhibin $A$ (male)

$(N=29, r=0.168, p=0.385, y=3.88-0.15 x)$

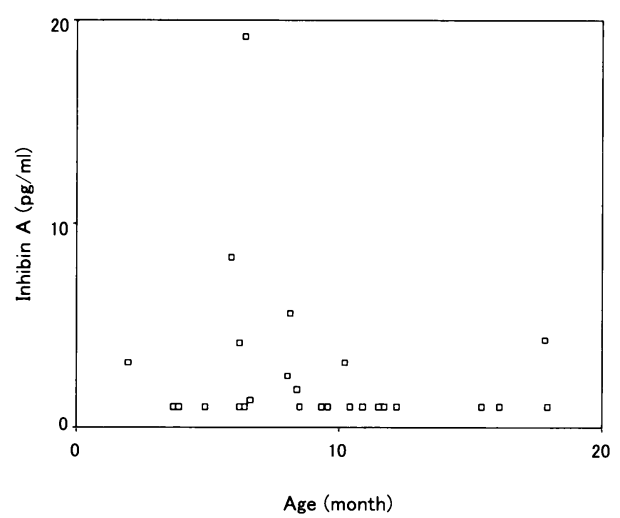

c) Inhibin $A$ (female)

$(N=24, r=0.310, p=0.14, y=10.36-0.62 x)$

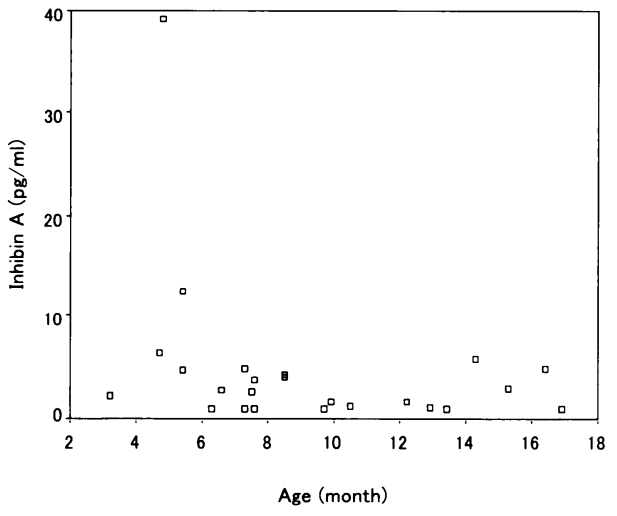

b) Inhibin $B$ (male)

$(N=29, r=0.500, p=0.006, y=373.76-15.0 x)$

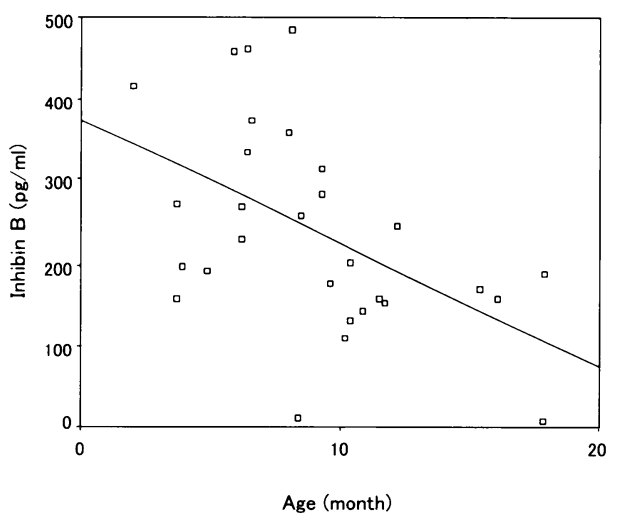

d) Inhibin $B$ (female) $(\mathrm{N}=24, r=0.52, p=0.009, y=125.46-6.66 \mathrm{x})$

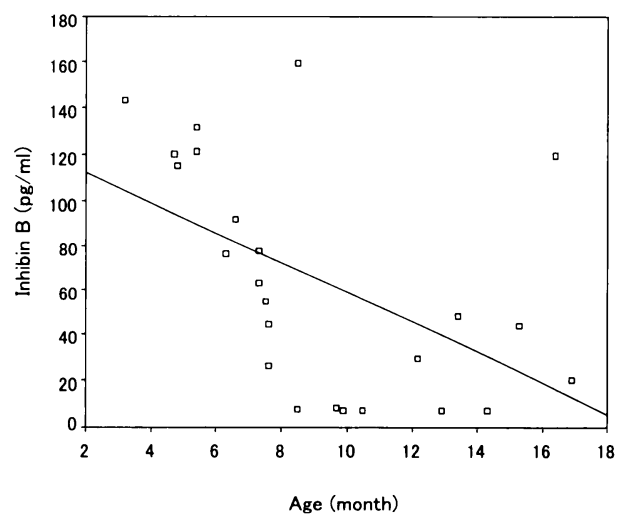

Fig. 1. Individual serum levels of inhibin $A$ and inhibin $B$ in relation to age Serum levels of inhibin A were significantly lower than those of inhibin B (male : $P<0.01$, female: $P<$ 0.01). a) Inhibin $A($ male $): \mathrm{N}=29, \mathrm{r}=0.168, P=0.385, \mathrm{y}=3.88-0.15 \mathrm{x} . \mathrm{b})$ Inhibin $\mathrm{B}$ (male) $: \mathrm{N}=29, \mathrm{r}=$ $0.500, P=0.006, \mathrm{y}=373.76-15.0 \mathrm{x}$. c) Inhibin A (female) : $\mathrm{N}=24, \mathrm{r}=0.310, P=0.14, \mathrm{y}=10.36-0.62 \mathrm{x} . \mathrm{d}$ ) Inhibin $\mathrm{B}$ (female) : $\mathrm{N}=24, \mathrm{r}=0.52, P=0.009, \mathrm{y}=125.46-6.66 \mathrm{x}$. In both genders, the serum concentrations of inhibin B were correlated with postnatal months of age in the simple regression analyses. No significant correlations were found between serum inhibin A levels and postnatal age.

studies showed that infants with low birth weight for their gestational age were associated with subfertility in both genders ${ }^{13,14}$. The relationship between serum inhibin B level and hypogonadism in SGA infants is controversial ${ }^{6,15-17)}$. Ibanez et al reported that the levels of serum inhibin B in infants born full-term SGA were similar to those appropriate for gestational age (AGA) infants but FSH levels were higher than those of AGA infants ${ }^{14)}$. They concluded that full-term SGA infants seem to need an augmented FSH drive to fulfill inhibin B requirements on the afferent side of the feedback loop ${ }^{14)}$. They also reported a normal inhibin B level and elevated FSH in adolescent girls born SGA, probably because of ovarian hyporesponsiveness to $\mathrm{FSH}^{16)}$. On the other hand, Cicognani et al reported that 
Table 2. Results of a multiple regression analysis with Inhibin B as the outcome variable Male

\begin{tabular}{ccccc}
\hline Variables & $\begin{array}{c}\text { Regression } \\
\text { Coefficient }\end{array}$ & SE & $\begin{array}{c}\text { Standardized Regression } \\
\text { Coefficient }\end{array}$ & P value \\
\hline Age & -15.4 & 4.72 & -0.513 & 0.03 \\
Birth weight SD score & 28.6 & 13.5 & 0.331 & 0.044 \\
\hline \multicolumn{2}{c}{ Female } & & & $\mathrm{R}^{2}=0.313 \quad(\mathrm{p}=0.003)$ \\
\hline Variables & Regression & SE & Standardized Regression & P value \\
& Coefficient & & Coefficient & \\
\hline Age & -6.86 & 2.38 & -0.524 & $<0.01$ \\
\hline
\end{tabular}

$R^{2}=0.242(p=0.009)$

Inhibin B concentration in males was significantly correlated with birth weight SD score and age. SE denotes standard error.

among postpubertal SGA subjects with small testicular size, the inhibin B level was low, and, for the SGA group, the inhibin B level was correlated with testicular size ${ }^{6)}$. They concluded that SGA subjects have impaired pituitary-gonadal axis function that show a tendency toward hypogonadism ${ }^{6}$. Morpurgo et al reported that the levels of inhibin $\mathrm{A}$ and $\mathrm{B}$ in umbilical cord blood were the highest in the intrauterine growth restriction group ${ }^{17)}$.

In the present study, inhibin B concentration in males was negatively correlated with the birth weight SD score until 18 months. The mechanisms of the reduced secretion of inhibin B in infants born SGA are currently unknown, but it is suspected that postnatal gonadal function may be affected by the intrauterine growth restriction in male infants. Although a follow-up study of serum inhibin B levels during infancy may predict future gonadal functions to some extent, it is still unclear whether we can regard serum inhibin B levels as a major determinant of spermatogenesis. Because this study included a small number of infants and individual data showed a wide deviation, possibly due to the wide ranges of gestational ages and birth weights, further studies are required to clarify whether or not serum inhibin B levels in infants born SGA can be a useful marker for the prediction of subsequent gonadal dysfunction.

\section{Conclusion}

In conclusion, our study suggests that prenatal growth may be one of the important factors that must be considered as a possible cause of subfertility in adult males.

\section{References}

1) Bergada I, Bergada C and Campo S: Role of inhibins in childhood and puberty. J Pediatr Endocrinol Metab $14: 343-353(2001)$

2) Knight PG and Glister C: Potential local regulatory functions of inhibins, activins and follistatin in the ovary. Reproduction $121: 503-512$ (2001)

3) Hayes FJ, Hall JE, Boepple PA and Crowley WF Jr: Clinical review 96: Differential control of gonadotropin secretion in the human: endocrine role of inhibin. J Clin Endocrinol Metab 83:1835-1841 (1998)

4) Andersson AM, Toppari J, Haavisto AM, Petersen JH, Simell T, Simell O and Skakkebaek NE: Longitudinal 
reproductive hormone profiles in infants : peak of inhibin B levels in infant boys exceeds levels in adult men. $J$ Clin Endocrinol Metab 83:675-681 (1998)

5) Andersson AM, Muller $\mathbf{J}$ and Skakkebaek NE: Different roles of prepubertal and postpubertal germ cells and Sertoli cells in the regulation of serum inhibin B levels. J Clin Endocrinol Metab 83 : 4451-4458 (1998)

6) Cicognani A, Alessandroni R, Pasini A, Pirazzoli P, Cassio A, Barbieri E and Cacciari E: Low birth weight for gestational age and subsequent male gonadal function. $J$ Pediatr $141: 376^{-379}$ (2002)

7) Barker DJ, Winter PD, Osmond C, Margetts B and Simmonds SJ : Weight in infancy and death from ischaemic heart disease. Lancet 2 : 577-580 (1989)

8) Illingworth PJ, Groome NP, Byrd W, Rainey WE, McNeilly AS, Mather JP and Bremner WJ : Inhibin-B : a likely candidate for the physiologically important form of inhibin in men. J Clin Endocrinol Metab 81:13211325 (1996)

9) Chada M, Prusa R, Bronsky J, Kotaska K, Sidlova K, Pechova M and Lisa L: Inhibin B, follicle stimulating hormone, luteinizing hormone and testosterone during childhood and puberty in males: changes in serum concentrations in relation to age and stage of puberty. Physiol Res 52:45-51 (2003)

10) Chada M, Prusa R, Bronsky J, Kotaska K, Sidlova K, Pechova M and Lisa L: Inhibin B, follicle stimulating hormone, luteinizing hormone, and estradiol and their relationship to the regulation of follicle development in girls during childhood and puberty. Physiol Res 52 : 341-346 (2003)

11) Anderson RA, Wallace EM, Groome NP, Bellis AJ and Wu FC: Physiological relationships between inhibin $\mathrm{B}$, follicle stimulating hormone secretion and spermatogenesis in normal men and response to gonadotrophin suppression by exogenous testosterone. Hum Reprod 12:746-751 (1997)

12) Andersson AM and Skakkebaek NE: Serum inhibin B levels during male childhood and puberty. Mol Cell Endocrinol 180 : 103-107 (2001)

13) Ibanez L, Valls C, Cols M, Ferrer A, Marcos MV and De Zegher F: Hypersecretion of FSH in infant boys and girls born small for gestational age. J Clin Endocrinol Metab 87 : 1986-1988 (2002)

14) Ibanez L, Potau $\mathrm{N}$ and de Zegher F: Ovarian hyporesponsiveness to follicle stimulating hormone in adolescent girls born small for gestational age. J Clin Endocrinol Metab $85: 2624-2626$ (2000)

15) de Bruin JP, Dorland M, Bruinse HW, Spliot W, Nikkels PG and Te Velde ER: Fetal growth retardation as a cause of impaired ovarian development. Early Hum Dev 51 : 39-46 (1998)

16) Francois I, de Zegher F, Spiessens C, D’Hooghe T and Vender Schueren D: Low birth weight and subsequent male subfertility. Pediatr Res $42: 899-901$ (1997)

17) Morpurgo PS, Cetin I, Borgato S, Cortelazzi D, Nobile-Desantis MS, Vaghi I and Beck-Peccoz P: Circulating levels of inhibin A, inhibin B and activin A in normal and intrauterine growth restricted (IUGR) fetuses. Eur J Obstet Gynecol Reprod Biol $117: 38-44$ (2004)

[Received November 17, 2005 : Accepted December 29, 2005] 